\title{
Older Underweight Pregnant Women Beat Young Overweight/Obese Ones on Incidence of Gestational Diabetes
}

\section{Feifei Li \\ Xuexin Zhou \\ Decui Cheng \\ Hongkun Wang \\ Xianming $\mathrm{Xu}$}

Department of Obstetrics and Gynecology, Shanghai General Hospital, Shanghai Jiao Tong University School of Medicine, Shanghai, 201600, People's

Republic of China
Correspondence: Hongkun Wang; Xianming $\mathrm{Xu}$

Department of Obstetrics and Gynecology, Shanghai General Hospital, Shanghai Jiao Tong University School of Medicine, 650 New Songjiang Road, Songjiang District, Shanghai, 20I600,

People's Republic of China

Email annie_coco@163.com; xuxmII@I63.com
Objective: This study aimed to compare the incidence of gestational diabetes mellitus (GDM) in older underweight pregnant women vs young overweight/obese ones.

Methods: A multiracial retrospective-cohort study was conducted in five hospitals of Shanghai on 7,485 women who had been pregnant during 2018-2020. Incidence of GDM was equal to the proportion of GDM cases in the total number of cases observed in the same period. Comparison of GDM incidence of older underweight pregnant women and young overweight/obese ones was done with $\chi^{2}$ tests. ORs and 95\% CIs for GDM were estimated using univariate and multivariate logistic regression across gestation age and prepregnancy BMI.

Results: Advanced age (OR 1.09, 95\% CI 1.072-1.11; $P=0$ ) and higher BMI (OR 1.57, 95\% CI 1.112-2.212; $P=0.01$ ) were found to be risk factors of GDM. The incidence of $13.33 \%$ of older underweight pregnant women (age $\geq 35$ years, BMI $<18.5 \mathrm{~kg} / \mathrm{m}^{2}$ ) developing GDM was lower than that of young overweight/obese ones (age $\leq 24$ years, BMI $\geq 24 \mathrm{~kg} / \mathrm{m}^{2}$ ). For those aged $\geq 35$ years, it is advised that BMI be kept to $<18.5 \mathrm{~kg} / \mathrm{m}^{2}$. For those aged $\leq 24$ years, BMI control should not exceed $24 \mathrm{~kg} / \mathrm{m}^{2}$.

Conclusion: Older underweight (age $\geq 35$ years, BMI $<18.5 \mathrm{~kg} / \mathrm{m}^{2}$ ) pregnant women beat young overweight/obese ones (age $\leq 24$ years, BMI $\geq 24 \mathrm{~kg} / \mathrm{m}^{2}$ ) on incidence of GDM. Factors influencing obesity/overweight in GDM were high maternal age, though being young is a promising protective factor for GDM and tolerance of BMI is promoted, but should be limited to certain ranges. Being older increased the chances of developing GDM, but those with lower BMI still had lower GDM incidence than younger pregnant women.

Keywords: gestational diabetes mellitus, GDM, prepregnancy body-mass index, pre-BMI, pregnancy outcome

\section{Introduction}

Gestational diabetes mellitus (GDM), the most common pregnancy complication, is defined as any degree of glucose intolerance with onset or first recognition during pregnancy, regardless of the degree of hyperglycemia. GDM affects approximately $14 \%$ of pregnancies worldwide, which represents approximately 18 million births annually, ${ }^{1}$ and this trend is getting even worse with the escalating obesity epidemic. Well-known risk factors of GDM include overweight and obesity, advanced maternal age, and a family history or any form of $\mathrm{DM},{ }^{2-5}$ though the specific pathophysiology or mechanisms underlying GDM are poorly defined. An ocean of studies have been performed to explore or demonstrate risk factors of GDM, while few have focused on 
looking for protective or counteractive factors can neutralize risk. Since advanced maternal age and obesity subsidize the process of GDM, being underweight and young press the development of GDM, what kind of BMI complicated with advanced pregnant women would offset the unfavorable impact of advanced age remains obscure, the same as maternal BMI. This article compares the incidence of GDM of older underweight pregnant women vs young overweight/ obese ones and explore upper BMI limits in young pregnant women and BMI ranges that can counteract the adverse effect of advanced age.

\section{Methods}

\section{Ethics}

This multiracial retrospective-cohort study was conducted in five hospitals in Shanghai: Shanghai General Hospital, Shanghai Changning District Maternal and Child Health Care Hospital, Shanghai Jiading District Maternal and Child Health Care Hospital, Shanghai First Maternal and Infant Health Hospital, and the International Peace Maternal and Child Health Center.

The study was approved by the ethics boards of these hospitals and conducted in accordance with the Declaration of Helsinki, and participants provided written informed consent. The trial was registered with Chinese Clinical Trial Registry (ChiCTR2000036575).

\section{Diagnosis of GDM}

GDM was diagnosed based on the International Association of Diabetes and Pregnancy Study Groups criteria: ${ }^{6}$ Women not previously diagnosed with DM undergo a $75 \mathrm{~g}$ oral glucose-tolerance test (OGTT) at 24 28 weeks of gestation, and plasma-glucose measurement was taken after the patient has fasted for 1 and 2 hours. The OGTT should be performed in the morning after an overnight fast of at least 8 hours. Diagnosis of GDM is made when any of the following plasma-glucose values are met or exceeded: fasting blood glucose (FBG) $92 \mathrm{mg} /$ $\mathrm{dL}(5.1 \mathrm{mmol} / \mathrm{L})$, and $\mathrm{BG}$ at 1 hour $\left(\mathrm{BG}_{1 \mathrm{~h}}\right) 180 \mathrm{mg} / \mathrm{dL}(10$ $\mathrm{mmol} / \mathrm{L})$ and 2 hours $\left(\mathrm{BG}_{2 \mathrm{~h}}\right) 153 \mathrm{mg} / \mathrm{dL}(8.5 \mathrm{mmol} / \mathrm{L})$.

\section{Study Population}

The data came from the clinical cards of pregnant women who had attended antenatal clinics and delivered in the aforementioned hospitals. The information on these cards comprises but is not limited to age, height, gravida, parity, prepregnancy weight, weight at different gestational stages, chronic disease complications, gestational complications, and previous GDM diagnosis. Prepregnancy body-mass index (pre-BMI) was divided into three groups: underweight (BMI $<18.5 \mathrm{~kg} / \mathrm{m}^{2}$ ), normal weight (BMI $18.5-23.9 \mathrm{~kg} / \mathrm{m}^{2}$ ), and overweight or obese (BMI $\geq 24 \mathrm{~kg} / \mathrm{m}^{2}$ ). Age was categorized into four groups: $\leq 24$ years old, $25-29$ years old, 30 34 years old, and $\geq 35$ years old.

Eligibility criteria were singleton pregnancy, regular antenatal checkups during pregnancy, and complete medical history. Exclusion criteria were DM diagnosed before pregnancy, history of GDM or macrosomia delivery, complications with gestational hypertension, preeclampsia, or any other chronic diseases, and gestational weight gain ${ }^{7}$ insufficient or excessive $(<5 \mathrm{~kg}$ or $>18 \mathrm{~kg})$.

Based on these criteria, 7,485 women attending antenatal clinics were enrolled, of which 1,111 had been diagnosed with GDM, accounting for $14.84 \%$ of the whole group. Those aged 25-29 years with BMI $18.5-23.9 \mathrm{~kg} / \mathrm{m}^{2}$ were used as the reference group.

\section{Statistical Analysis}

Data normality was evaluated using the skewness-kurtosis test. Binary outcomes are presented as relative risks with $95 \%$ CIs. Age, height, weight, $\mathrm{BMI}, \mathrm{FBG}, \mathrm{BG}_{1 \mathrm{~h}}$, and $\mathrm{BG}_{2 \mathrm{~h}}$ were regarded as continuous variables, while times of gravida, parity, and complications with first family history were taken as categorical variables. Continuous variables were analyzed by means of ANOVA, and are expressed as means \pm if they were normally distributed and as means of nonparametric tests if their distribution was abnormal. Age, height, weight, $\mathrm{BMI}, \mathrm{FBG}, \mathrm{BG}_{1 \mathrm{~h}}$, and $\mathrm{BG}_{2 \mathrm{~h}}$ were distributed normally. The incidence of GDM was equal to the proportion of GDM cases in the total number of cases observed in the same period. $\chi^{2}$ tests were used to compare disordered categorical variables between and among groups. ORs and 95\% CIs for GDM were estimated using univariate and multivariate logistic regression, and confounders included gravida, parity, gestational age at OGTT examination, and maternal family history of DM and hypertension. Statistical significance was regarded as $P<0.05$.

\section{Results}

\section{Characteristics of Participants}

Baseline characteristics for each group are outlined in Table 1. There were 7,485 pregnant women enrolled in this study. There were 1,111 GDM cases (14.84\%). As presented 
Table I Characteristics of those Studied

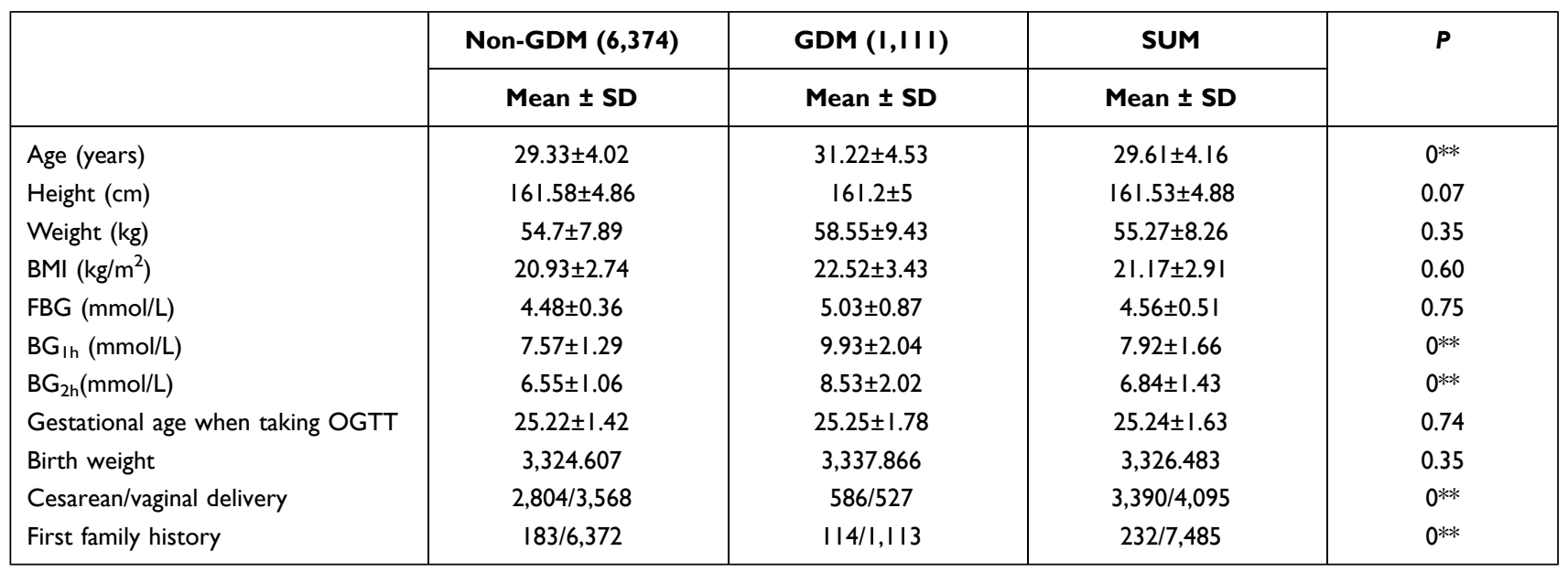

Notes: Fasting and I- and 2-hour blood glucose are OGTT results. $* * P<0.01$.

Abbreviations: BMI, body mass index, GDM, gestational diabetes, FBG, fasting blood glucose.

in Table 1, those with GDM were older and heavier than those without. Pregnant women with GDM had higher rates of cesarean delivery and a family history of DM (Table 1).

\section{GDM Risk Factors}

On bivariate logistic regression analyses, factors significantly increasing the risk of GDM were age, gravida, parity, height, prepregnancy weight, and BMI. On multivariate logistic regression analysis, only age (OR 1.09, 95\% CI 1.072 $1.11 ; P=0)$ and BMI (OR 1.57, 95\% CI 1.112-2.212; $P=0.01$ ) reached statistical significance (Table 2 ).

Age was classified into four groups: $\leq 24,25-29,30-34$, and $\geq 35$ years. Based on classification criteria for the Chinese population, BMI was stratified into three layers: $<18.5 \mathrm{~kg} /$ $\mathrm{m}^{2}, 18.5-23.9 \mathrm{~kg} / \mathrm{m}^{2}$, and $\geq 24 \mathrm{~kg} / \mathrm{m}^{2}$. After permutation and combination of the two subgroups, the entire population was categorized into 12 groups, listed in Table 3.

Age 25-29years and BMI 18.5-23.9 kg/m² were set as reference group. ORs for the other groups were then calculated. Age $\geq 35$ years and BMI $\geq 24 \mathrm{~kg} / \mathrm{m}^{2}$ (OR $6.458,95 \%$ CI 4.74
8.798; $P=0$ ) topped the list, age $30-34$ years and BMI $\geq 24 \mathrm{~kg} /$ $\mathrm{m}^{2}$ (OR 3.564, 95\% CI 2.743-4.63; $P=0$ ) was second, and then followed by the branch of age $\geq 35$ years and BMI 18.5-23.9 $\mathrm{kg} / \mathrm{m}^{2}$ (OR 3.113, 95\% CI 2.497-3.88; $P=0$ ). Interestingly, older underweight pregnant beat young overweight ones in terms of chance of developing GDM, because the OR for age $\geq 35$ years and BMI $<18.5 \mathrm{~kg} / \mathrm{m}^{2}$ was only $1.414(95 \% \mathrm{CI}$ 0.664-3.014, $P=0.037$ ) while that for age $\leq 24$ years and BMI $\geq 24 \mathrm{~kg} / \mathrm{m}^{2}$ was 3.009 (95\% CI 1.737-5.212, $P=0$; Table 4).

\section{Crossover Analysis of Age and BMI for Incidence of GDM}

GDM incidence in each group was calculated (Table 5). The lowest incidence (3.85\%) was unsurprisingly in the age $\leq 24$ years and BMI $<18.5 \mathrm{~kg} / \mathrm{m}^{2}$ group, while the highest incidence $(41.26 \%)$ was in the age $\geq 35$ years and $\mathrm{BMI} \geq 24 \mathrm{~kg} / \mathrm{m}^{2}$ group. The rate of GDM in the age $\leq 24$ years and $\mathrm{BMI} \geq 24 \mathrm{~kg} / \mathrm{m}^{2}$ group was $22.5 \%$ versus

Table 2 Risk Factors of GDM

\begin{tabular}{|l|c|c|c|c|c|c|}
\hline & $P$ & OR & $95 \% \mathbf{C l}$ & Adjusted $\boldsymbol{P}$ & Adjusted OR & Adjusted 95\% CI \\
\hline Age** & 0 & 1.11 & $1.097-1.13$ & 0 & 1.09 & $1.072-1.11$ \\
Gravida & 0 & 1.23 & $1.169-1.297$ & 0.90 & 1.00 & $0.928-1.068$ \\
Para & 0 & 1.59 & $1.423-1.773$ & 0.06 & 1.17 & $1.015-1.35$ \\
Height & 0.02 & 0.98 & $0.971-0.997$ & 0.19 & 1.07 & $0.968-1.173$ \\
Weight & 0 & 1.05 & $1.044-1.059$ & 0.09 & 0.90 & $0.786-1.019$ \\
BMI** & 0 & 1.18 & $1.157-1.204$ & 0.01 & 1.57 & $1.112-2.212$ \\
First-degree DM history** & 0 & 1.89 & $1.484-2.4 I 1$ & 0 & 1.78 & $1.375-2.296$ \\
\hline
\end{tabular}

Notes: $* * P<0.01$.

Abbreviations: BMI, body-mass index; GDM, gestational diabetes mellitus. 
Table 3 Variables Based on BMI and Age

\begin{tabular}{|c|c|c|c|c|c|c|c|}
\hline & Age & $\begin{array}{c}\text { Height } \\
(\mathrm{cm})\end{array}$ & $\begin{array}{c}\text { Weight } \\
\text { (kg) }\end{array}$ & $\begin{array}{c}\text { BMI } \\
\left(\mathrm{kg} / \mathrm{m}^{2}\right)\end{array}$ & $\begin{array}{c}\text { FBG } \\
(\mathrm{mmol} / \mathrm{L})\end{array}$ & $\begin{array}{c}B G_{\mathrm{Ih}} \\
(\mathrm{mmol} / \mathrm{L})\end{array}$ & $\begin{array}{c}\mathbf{B G}_{2 \mathrm{~h}} \\
(\mathrm{mmol} / \mathrm{L})\end{array}$ \\
\hline Age $\leq 24, \mathrm{BMI}<18.5$ (I56) & $22.65 \pm 1.49$ & $161.98 \pm 4.73$ & $46.03 \pm 3.44$ & $17.53 \pm 0.83$ & $4.49 \pm 0.45$ & $7.31 \pm 1.67$ & $6.45 \pm 1.35$ \\
\hline Age $\leq 24$, BMI $\leq 18.5-\leq 23.9(405)$ & $22.92 \pm 1.46$ & $162.04 \pm 5.04$ & $54.36 \pm 5.26$ & $20.68 \pm 1.47$ & $4.52 \pm 0.49$ & $7.37 \pm 1.63$ & $6.52 \pm 1.35$ \\
\hline Age $\leq 24, \mathrm{BMI} \geq 24(80)$ & $22.73 \pm 1.73$ & $162.82 \pm 6.16$ & $71.23 \pm 7.86$ & $26.84 \pm 2.24$ & $4.7 I \pm 0.56$ & $8.05 \pm 1.86$ & $6.58 \pm 1.79$ \\
\hline Age $\leq 25-\leq 29, \mathrm{BMI}<18.5(623)$ & $27.2 \pm 1.36$ & $161.73 \pm 4.87$ & $45.83 \pm 3.32$ & $|7.5| \pm 0.79$ & $4.44 \pm 0.37$ & $7.56 \pm 1.45$ & $6.68 \pm 1.28$ \\
\hline Age $\leq 25-\leq 29, \mathrm{BMI} \leq 18.5-\leq 23.9(2,319)$ & $27.33 \pm 1.33$ & $161.73 \pm 4.8$ & $54.37 \pm 5.02$ & $20.76 \pm 1.43$ & $4.52 \pm 0.48$ & $7.7 I \pm I .55$ & $6.7 I \pm 1.30$ \\
\hline Age $\leq 25-\leq 29, \mathrm{BMI} \geq 24(4 \mid 4)$ & $27.35 \pm 1.32$ & $|6| .5 \pm 5.1 \mid$ & $69.38 \pm 7.91$ & $26.57 \pm 2.47$ & $4.68 \pm 0.75$ & $8.32 \pm 1.99$ & $7.06 \pm 1.80$ \\
\hline Age $\leq 30-\leq 34, \mathrm{BMI}<18.5$ (289) & $30 \pm 0.56$ & $|6| .27 \pm 4.62$ & $45.93 \pm 3.11$ & $17.65 \pm 0.68$ & $4.47 \pm 0.39$ & $7.62 \pm 1.39$ & $6.65 \pm 1.43$ \\
\hline Age $\leq 30-\leq 34, \mathrm{BMI} \leq 18.5-\leq 23.9(1,870)$ & $31.37 \pm 1.06$ & $|6| .47 \pm 4.86$ & $54.5 \pm 5$ & $20.89 \pm 1.45$ & $4.55 \pm 0.46$ & $8 \pm 1.58$ & $6.87 \pm 1.33$ \\
\hline Age $\leq 30-\leq 34, \mathrm{BMI} \geq 24$ (383) & $33.89 \pm 0.31$ & $160.95 \pm 5.08$ & $68.5 \pm 7.43$ & $26.42 \pm 2.33$ & $4.7 I \pm 0.60$ & $8.7 I \pm I .8 I$ & $7.26 \pm 1.60$ \\
\hline Age $\geq 35, \mathrm{BMI}<18.5(60)$ & $36.78 \pm 2.58$ & $160.93 \pm 4.76$ & $45.78 \pm 3.25$ & $17.66 \pm 0.67$ & $4.58 \pm 0.51$ & $7.92 \pm 1.37$ & $6.87 \pm 2.28$ \\
\hline Age $\geq 35$, BMI $\leq 18.5-\leq 23.9(680)$ & $37 \pm 2.04$ & $160.99 \pm 4.59$ & $55.03 \pm 4.97$ & $21.21 \pm 1.48$ & $4.59 \pm 0.51$ & $8.34 \pm 1.64$ & $7.14 \pm 1.53$ \\
\hline Age $\geq 35, \mathrm{BMI} \geq 24$ (206) & $37.22 \pm 2.39$ & $160.77 \pm 5.45$ & $67.76 \pm 7.03$ & $26.19 \pm 2.17$ & $4.89 \pm 0.79$ & $8.96 \pm 1.93$ & $7.61 \pm 1.75$ \\
\hline
\end{tabular}

Notes: Fasting I- and 2-hour blood glucose are OGTT results. Units of age and BMI are years and $\mathrm{kg} / \mathrm{m}^{2}$, respectively. Abbreviations: BMI, body-mass index, FBG, fasting blood glucose.

Table 4 ORs of GDM

\begin{tabular}{|l|c|c|c|c|}
\hline & Wald & $P$ & OR & $95 \%$ CI \\
\hline Age $\leq 24, \mathrm{BMI}<18.5$ & 5.617 & 0.018 & 0.368 & $0.161-0.84 I$ \\
Age $\leq 24, \mathrm{BMI} \leq 18.5-\leq 23.9$ & 3.368 & 0.046 & 0.683 & $0.454-1.026$ \\
Age $\leq 24, \mathrm{BMI} \geq 24$ & 15.436 & 0 & 3.009 & $1.737-5.212$ \\
Age $\leq 30-\leq 34, \mathrm{BMI}<18.5$ & 1.914 & 0.017 & 0.720 & $0.453-1.146$ \\
Age $\leq 30-\leq 34, \mathrm{BMI}$ & 35.385 & 0 & 1.750 & $1.455-2.104$ \\
$\leq 18.5-\leq 23.9$ & & & & \\
Age $\leq 30-\leq 34, \mathrm{BMI} \geq 24$ & 90.573 & 0 & 3.564 & $2.743-4.63$ \\
Age $\geq 35, \mathrm{BMI}<18.5$ & 0.806 & 0.037 & 1.414 & $0.664-3.014$ \\
Age $\geq 35, \mathrm{BMI}$ & 101.953 & 0 & 3.113 & $2.497-3.88$ \\
$\leq 18.5-\leq 23.9$ & & & & \\
Age $\geq 35, \mathrm{BMI} \geq 24$ & 139.776 & 0 & 6.458 & $4.74-8.798$ \\
Age $\leq 25-\leq 29, \mathrm{BMI}<18.5$ & 4.388 & 0.036 & 0.699 & $0.499-0.977$ \\
Age $\leq 25-\leq 29, \mathrm{BMI} \geq 24$ & 54.756 & 0 & 2.738 & $2.097-3.575$ \\
Age $\leq 25-\leq 29, \mathrm{BMI}$ & & & $\mathrm{I}$ & \\
$\leq 18.5-\leq 23.9$ & & & \multicolumn{3}{|l}{} \\
\hline
\end{tabular}

Notes: Units of age and BMI are years and $\mathrm{kg} / \mathrm{m}^{2}$, respectively.

Abbreviations: GDM, gestational diabetes mellitus, BMI, body-mass index.

$13.33 \%$ for the age $\geq 35$ years and $\mathrm{BMI}<18.5 \mathrm{~kg} / \mathrm{m}^{2}$ group. GDM rates in those aged $\leq 24,25-29,30-34$, and $\geq 35$ years were $8.11 \%, 10.94 \%, 16.80 \%$, and $28.01 \%$, respectively. When comparing the incidence of GDM based on BMI category, $7 \%$ was observed for $<18.5 \mathrm{~kg} / \mathrm{m}^{2}$, while $13.78 \%$ and $28.16 \%$ were found for $18.5-23.9 \mathrm{~kg} / \mathrm{m}^{2}$ and $\geq 24.0 \mathrm{~kg} / \mathrm{m}^{2}$, respectively (Table 5).

\section{Discussion}

Advanced maternal age, overweight, and obesity are widely accepted risk factors of GDM. ${ }^{8,9}$ In this study, advanced age and high BMI again proved to be risk factors of GDM. Based on our data, GDM incidence in older underweight pregnant women $(\geq 35$ years old, BMI $<18.5 \mathrm{~kg} / \mathrm{m}^{2}$ ) was lower than young overweight ones ( $\leq 24$ years old, BMI $\left.\geq 24 \mathrm{~kg} / \mathrm{m}^{2}\right)$.

To support the needs of a growing fetus, a mother's body undergoes a series of physiological changes during a healthy pregnancy, of which insulin sensitivity changes over the course of gestation. During the first trimester, insulin sensitivity increases, promoting glucose entry into adipose cells with the purpose of conserving energy for later stages of pregnancy. ${ }^{10}$ However, as the pregnancy progresses, ever-growing levels of hormones, including human placental lactogen (also known as choriomammotropin) and placental growth hormone mediated by placenta, ${ }^{11}$ are released into the circulation and consequently insulin resistance is promoted. Mildly elevated BG is transported across the placenta to fuel the growth of the fetus, and this slightly elevated state of insulin resistance also stimulates endogenous glucose production and the breakdown of fat stores, inducing a further increase in BG and free fatty-acid concentrations. Increased glucose-stimulated insulin secretion and hypertrophy and hyperplasia of pancreatic $\beta$-cells tend to maintain glucose homeostasis and make up for these unfavorable changes. ${ }^{12}$

Numerous studies have suggested that women who develop GDM have evidence of metabolic dysfunction before conception, including pancreatic $\beta$-cell defects and increased insulin resistance. ${ }^{13}$ Most women who develop GDM are overweight/obese or older, which are related to 
Table 5 GDM by group

\begin{tabular}{|c|c|c|c|c|}
\hline Age $\leq 24$ & BMI $<18.5$ & $\begin{array}{c}\text { BMI } \\
\leq 18.5-\leq 23.9\end{array}$ & BMI $\geq 24$ & Sum \\
\hline GDM & 6 & 28 & 18 & 52 \\
\hline Non-GDM & 150 & 377 & 62 & 589 \\
\hline Sum & 156 & 405 & 80 & 641 \\
\hline $\begin{array}{l}\text { GDM } \\
\text { incidence }\end{array}$ & $3.85 \%$ & $6.91 \%$ & $22.50 \%$ & $8.11 \%$ \\
\hline $\begin{array}{l}\text { Age } \\
\leq 25-\leq 29\end{array}$ & BMI $<18.5$ & $\begin{array}{c}\text { BMI } \\
\leq 18.5-\leq 23.9\end{array}$ & $\mathrm{BMI} \geq 24$ & Sum \\
\hline GDM & 44 & 228 & 95 & 367 \\
\hline Non-GDM & 579 & 2,091 & 319 & 2,989 \\
\hline Sum & 623 & 2,319 & $4 \mid 4$ & 3,356 \\
\hline $\begin{array}{l}\text { GDM } \\
\text { incidence }\end{array}$ & $7.06 \%$ & $9.83 \%$ & $22.95 \%$ & $10.94 \%$ \\
\hline $\begin{array}{l}\text { Age } \\
\leq 30-\leq 34\end{array}$ & $\mathrm{BMI}<18.5$ & $\begin{array}{c}\text { BMI } \\
\leq 18.5-\leq 23.9\end{array}$ & $\mathrm{BMI} \geq 24$ & Sum \\
\hline GDM & 21 & 299 & 107 & 427 \\
\hline Non-GDM & 268 & $|57|$ & 276 & 2115 \\
\hline Sum & 289 & 1870 & 383 & 2542 \\
\hline $\begin{array}{l}\text { GDM } \\
\text { incidence }\end{array}$ & $7.27 \%$ & $15.99 \%$ & $27.94 \%$ & $16.80 \%$ \\
\hline Age $\geq 35$ & BMI $<18.5$ & $\begin{array}{c}\text { BMI } \\
\leq 18.5-\leq 23.9\end{array}$ & BMI $\geq 24$ & Sum \\
\hline GDM & 8 & 172 & 85 & 265 \\
\hline Non-GDM & 52 & 508 & 121 & 681 \\
\hline Sum & 60 & 680 & 206 & 946 \\
\hline $\begin{array}{l}\text { GDM } \\
\text { incidence }\end{array}$ & $13.33 \%$ & $25.29 \%$ & $41.26 \%$ & $28.01 \%$ \\
\hline GDM & 79 & 727 & 305 & $I, I I I$ \\
\hline Non-GDM & 1,049 & 4,547 & 778 & 6,374 \\
\hline Sum & $\mathrm{I}, 128$ & 5,274 & 1,083 & 7,485 \\
\hline $\begin{array}{l}\text { GDM } \\
\text { incidence }\end{array}$ & $7.00 \%$ & $13.78 \%$ & $28.16 \%$ & $14.84 \%$ \\
\hline
\end{tabular}

Notes: Units of age and $\mathrm{BMl}$ are years old and $\mathrm{kg} / \mathrm{m}^{2}$, respectively. GDM incidence is equal to GDM/sum.

Abbreviations: GDM, gestational diabetes mellitus, BMI, body-mass index.

inflammatory status. ${ }^{14}$ The progress of pregnancy and associated metabolic changes (increased insulin resistance and demand for increased $\beta$-cell response) causes insulin to be less effective in suppressing endogenous glucose production and glucose uptake, and thus can lead to clinical hyperglycemia. ${ }^{13}$

Obesity is a proinflammatory state in which both hypertrophic adipocytes and immune cells (mainly lymphocytes and macrophages) in adipose tissue introduce increased circulating levels of proinflammatory cytokines.
Obesity-related chronic low-grade systemic inflammation, known as "metabolic inflammation", is considered the focus of insulin resistance and the pathogenesis of DM in humans and rodent models. ${ }^{15,16}$

Laine et $\mathrm{al}^{17}$ assessed the effects of age and obesity on GDM in primiparous pregnant women, and found that the risk of GDM increased with maternal age after adjusting for pre-BMI and number of previous pregnancies. An almost universal finding of the risk of GDM increasing linearly with age has been reported in the literature, although the degree of GDM risk varies from study to study. The exact mechanism of the association between maternal age and GDM has not been clearly proven, and high levels of insulin resistance, circulating adipokines, and inflammatory markers and oxidative stress may partially explain this phenomenon. ${ }^{18,19}$

\section{Conclusion}

This study is the first in China to compare the incidence of GDM in older underweight pregnant women vs young overweight/obese ones, and was inspired by the doubt of pregnant women at clinic. These ladies are just curious about the incidence of GDM they will be diagnosed and they compared with the others'. Our data indicated that the influence of obesity/overweight was higher than advanced maternal age, resulting in the rate of GDM in older underweight pregnant women being lower than young overweight/obese ones, which is logical yet new information, as no such research has been conducted before. The final results warn us there should be limitations to the upper BMI range in young expectant mothers for the purpose of avoiding GDM, and also shed light on lowering the chance of GDM in advanced pregnancies.

Limitations of this study include prepregnancy weight being self-reported and all the data coming from five hospitals; therefore, there may exist information bias regarding the original data. It is well known that GDM is influenced by multitudinous factors. Our research focused on the main two factors, but other characteristics were excluded, which is a little one-sided. The data were divided only into GDM and non-GDM, and GDM severity and treatment was not stratified further. The number of women whose BMI indicated obesity or overweight was limited and those of advanced age were rare, so the layers of age and BMI were a little bit rough. We expect to enroll more patients in the near future to perform further deeper research. 


\section{Data Sharing Statement}

The data sets used and/or analyzed in this current study are available from the corresponding authors on reasonable request.

\section{Acknowledgments}

The research group gratefully acknowledges the commitment and dedication of all the participants.

\section{Author Contributions}

All authors made substantial contributions to conception and design, acquisition of data, or analysis and interpretation of data, took part in drafting the article or revising it critically for important intellectual content, agreed to submit to the current journal, gave final approval to the version to be published, and agree to be accountable for all aspects of the work.

\section{Funding}

This research was sponsored by the Clinical Research Plan of SHCD.

\section{Disclosure}

The authors report no conflicts of interest.

\section{References}

1. American Diabetes Association. Standards of medical care in diabetes-20182. classification and diagnosis of diabetes. Diabetes Care. 2018;41(null):S13-S27. doi:10.2337/dc18-S002.

2. Wang $\mathrm{C}$, Wei $\mathrm{Y}$, Zhang $\mathrm{X}$, et al. A randomized clinical trial of exercise during pregnancy to prevent gestational diabetes mellitus and improve pregnancy outcome in overweight and obese pregnant women. Am J Obstet Gynecol. 2017;216:340-351. doi:10.1016/j.ajog.2017.01.037

3. van Hoorn F, Koster MPH, Naaktgeboren CA, et al. Prognostic models versus single risk factor approach in first-trimester selective screening for gestational diabetes mellitus: a prospective population-based multicentre cohort study. BJOG. 2021;128(4):645-654. doi:10.1111/1471-0528.16446

4. Katrien B, Paul VC, Carolien M, et al. Risk factor screening for gestational diabetes mellitus based on the 2013 WHO criteria. Eur $J$ Endocrinol. 2019;180(6):353-363. doi:10.1530/EJE-19-0117

5. Kahiira NB, Araali NA, Joha NM. Burden, risk factors and maternal and offspring outcomes of gestational diabetes mellitus (GDM) in sub-Saharan Africa (SSA): a systematic review and meta-analysis. BMC Pregnancy Childbirth. 2019;19(1):450. doi:10.1186/s12884019-2593-z
6. Metzger BE, Coustan DR, Trimble ER; HAPO Study Cooperative Research Group. Hyperglycemia and adverse pregnancy outcomes. N Engl J Med. 2008;358:1991-2002. doi:10.1056/NEJMoa0707943.

7. Rasmussen KM, Yaktine AL, editors. Weight Gain During Pregnancy: Reexamining the Guidelines. Washington (DC): National Academies Press (US); 2009. PMID: 20669500.

8. Liu X, Zou L, Yi C, Yan R, Zhang W. Effects of maternal age on pregnancy: a retrospective cohort study. Natll Med J China. 2014;94 (25):1984-1988. doi:10.3760/cma.j.issn.0376-2491.2014.25.017

9. Laura S, Hutcheon Jennifer A, Hacker Michele R, et al. Absolute risks of obstetric outcomes by maternal age at first birth: a population-based cohort. Epidemiology. 2018;29(3):379-387. doi:10.1097/EDE.0000000000000818

10. Di Cianni G, Miccoli R, Volpe L, Lencioni C, Del Prato S. Intermediate metabolism in normal pregnancy and in gestational diabetes. Diabetes Metab Res Rev. 2003;19:259-270. doi:10.1002/ dmrr.390

11. McIntyre HD. Discovery, knowledge, and action-diabetes in pregnancy across the translational spectrum: the 2016 Norbert Freinkel award lecture. Diabetes Care. 2018;41:227-232. doi:10.2337/dci17-0056

12. Plows Jasmine F, Stanley Joanna L, Baker Philip N, Reynolds Clare M, Vickers Mark H. The pathophysiology of gestational diabetes mellitus. Int J Mol Sci. 2018;19(11):undefined. doi:10.3390/ ijms 19113342

13. Catalano PM, Huston L, Amini SB, Kalhan SC. Longitudinal changes in glucose metabolism during pregnancy in obese women with normal glucose tolerance and gestational diabetes mellitus. $\mathrm{Am}$ J Obstet Gynecol. 1999;180:903-916. doi:10.1016/s0002-9378(99) 70662-9

14. Hotamisligil GS, Peraldi P, Budavari A, Ellis R, White MF, Spiegelman BM. IRS-1-mediated inhibition of insulin receptor tyrosine kinase activity in TNF-alpha- and obesity-induced insulin resistance. Science. 1996;271(5249):665-670. doi:10.1126/science.27 1.5249 .665

15. Gregor MF, Hotamisligil GS. "Inflammatory mechanisms in obesity". Annu Rev Immunol. 2011;29:415-445. doi:10.1146/annurev-immunol $-031210-101322$

16. Ouchi N, Parker JL, Lugus JJ, Walsh K. “Adipokines in inflammation and metabolic disease". Nat Rev Immunol. 2011;11(2):85-97. doi:10. 1038/nri2921

17. Laine MK, Kautiainen H, Gissler M, et al. Gestational diabetes in primiparous women-impact of age and adiposity: a register-based cohort study. Acta Obstet Gynecol Scand. 2018;97(2):187-194. doi:10.1111/aogs.13271

18. Shin D, Song WO. Prepregnancy body mass index is an independent risk factor for gestational hypertension, gestational diabetes, preterm labor, and small- and large-for-gestational-age infants. J Matern Fetal Neonatal Med. 2015;28(14):1679-1686. doi:10.3109/14767058.2014. 964675

19. Fontana L, Eagon JC, Trujillo ME, Scherer PE, Klein S. Visceral fat adipokine secretion is associated with systemic inflammation in obese humans. Diabetes. 2007;56(4):1010-1013. doi:10.2337/db06-1656

\section{Publish your work in this journal}

Diabetes, Metabolic Syndrome and Obesity: Targets and Therapy is an international, peer-reviewed open-access journal committed to the rapid publication of the latest laboratory and clinical findings in the fields of diabetes, metabolic syndrome and obesity research. Original research, review, case reports, hypothesis formation, expert opinion and commentaries are all considered for publication. The manuscript management system is completely online and includes a very quick and fair peer-review system, which is all easy to use. Visit http://www.dovepress.com/testimonials.php to read real quotes from published authors. 